\title{
Triad Model of Education (II) and Instructional Engineering
}

\author{
E. A. Vargas \\ B. F. Skinner Foundation
}

Despite the money and sweat that go into new instructional technologies, they do not produce the overall high level of student performances that societies seek. More effective teaching calls for a profound solution. It requires a coordinate triad of factors: a proper science, the correct organizational structure, and an engineering instructional technology. This second of a series of articles on the Triad Model of Education concentrates on instructional engineering. The instructional engineering drawn from the science is contingency-based. Contingency-based instructional systems always handle the inevitable two components of instruction: the repertoires of students and the setups that shape those repertoires. The setup component features five elements: subject matter, objectives, quality control, presentation modes, and logistics. The repertoire component consists of the governance of repertoires - event and lingual governed, the type of repertoire-knowing, solving, and creating, and the variability of the repertoire-convergent and divergent. These elements, and their required engineering, reveal an instructional task more complex than previously considered. Progress with such complexity occurs only when all components of the triad are in place.

Keywords: Triad Model of Education, behaviorology, collaborative organization, contingencybased instruction

\begin{abstract}
A pesar del dinero y el sudor que forman parte de las nuevas tecnologías instructivas, no producen el alto nivel global de logro por parte de los estudiantes que las sociedades buscan. Una enseñanza más efectiva requiere una solución profunda. Requiere una tríada coordinada de factores: una ciencia adecuada, una estructura organizacional correcta y una tecnología instructiva de ingeniería. Este segundo artículo de una serie de artículos sobre el Modelo Tríada de Educación se centra en la ingeniería instructiva. La ingeniería instructiva extraída de la ciencia se basa en las contingencias. Los sistemas basados en contingencias siempre manejan los dos componentes inevitables de la instrucción: los repertorios de los estudiantes y los contextos o escenarios que dan forma a dichos repertorios. El componente contextual consta de cinco elementos: la asignatura, los objetivos, el control de la calidad, los modos de presentación y la logística. El componente del repertorio consiste en el gobierno de los repertorios-gobernados por eventos y por la lengua, el tipo de repertorio-saber, resolver y crear y la variabilidad del repertorio-convergente y divergente. Estos elementos y su ingeniería necesaria revelan una tarea instructiva más compleja de lo que se había pensado con anterioridad. El progreso con dicha complejidad sólo ocurre cuando todos los componentes de la tríada se encuentran en su lugar.

Palabras clave: modelo tríada de educación, conductología, organización colaborativa, instrucción basada en contingencias
\end{abstract}

Correspondence concerning this article should be addressed to E. A. Vargas, B. F. Skinner Foundation, Suite 3003, 12 Arrow Street, Cambridge, MA, 02138, USA. E-mail: eavargas@bfskinner.org 
Failure of Instructional Technology

Everyone assumes that a better instructional technology will solve the problem of teaching more effectively. All sorts of hopes are raised over the latest technique or tool. No year passes without extraordinary enthusiasm over a new technique such as discovery learning or direct instruction or precision teaching or personalized system of instruction. And from time to time, a gadget such as the computer, or its offspring the internet, is hailed as the final breakthrough from the reality of dismal instruction to the dream of effective teaching. Yet, none of these tools and techniques succeed as promised. Evidently, the presumption is wrong.

We reach a conclusion that is nonintuitive but nevertheless correct. A good instructional technology is not sufficient for instructional success. Two wonderful instructional innovations were programmed instruction (p.i.) and the personalized system of instruction (p.s.i.). Both failed. They failed not because they could not instruct effectively. In the hands of those who knew the science and who had the proper organization resource base, both p.i. and p.s.i. instructed well. They failed for two reasons.

First, a huge disconnect developed between these instructional technologies and the science from which they derived. People who knew little of the background science of these technologies jumped onto what was then a fast moving bandwagon. The bandwagon came to a stop because these people did not know how to feed the horses. They adopted the forms of the procedures without understanding the processes responsible for the procedures. They went through the motions without understanding the dynamics behind the motions. They prescribed actions without designing the contingencies that give meaning to actions. Given this lack of scientific understanding, it is no surprise these technologies, by and large, halted. Continual success with any technology requires a savvy discernment of its underlying science. It requires engineers.

Second, a consistently overlooked factor also played its part. As just pointed out and everyone acknowledges, a technology necessitates competent practitioners to carry it out. But success in applying any technology demands even more than that obvious requirement. It further demands the organization of practitioners in a manner that efficiently achieves the social aims of that technology. Only through organized endeavor do technologies achieve their aims. A proper division of labor is needed. From movie-making to complex surgery, the allocation of various specialized repertoires to achieve a common goal constitutes the vital principle of organized endeavor. On top of that, it is necessary to coordinate and control effectively the assorted forms of activities relevant to technical endeavor. Without the proper organization of a novel technology, little can be accomplished. But currently, educational institutions are organized for an outmoded technology.

\section{The Triad Model of Education}

Who can object to a better instructional technology, either of tools or of techniques? Everyone can easily agree on its necessity. But more is needed. Traditional educators as well as behaviorists, behavior analysts, and behaviorologists, hold too narrow a focus. They concentrate only on instructional technology. But advancing a good teaching technique is not sufficient for educational success. That technique requires active connection to the science from which it derives. Such a connection calls for people who know how to make that connection. As important, to execute effectively any technology necessitates the proper division of labor and that labor's proper control and coordination. If these other aspects of a social innovation are not in place, then success occurs rarely, or haphazardly, or not at all.

As Skinner (1968, p. 5) pointed out, “... teaching is simply the arrangement of contingencies of reinforcement." But the definition makes a demand. The simple definition encapsulates a complex prerequisite. Arrangements cannot be made without having arrangers. These arrangers must be skilled for arrangements to work as they should. The necessary skills derive from the science that analyzes contingency arrangements. And these arrangements, especially in dealing with large numbers of diverse repertoires, should not be handled as if their components did not affect each other. Instructional arrangements are systems whose components must coordinate with each other. Furthermore, the depth and extent of these components involve specialized skills. Contingency arrangers work with others whose skills complement theirs so they can accomplish together what they cannot achieve separately.

For eventual success, the problem of instructional effectiveness demands a broad based solution. Its solution in any educational setting takes a trio of factors: science, organization, and engineering. None by itself will sustain instructional effectiveness. Each part of this triadic set can be considered separately, but they work jointly. In education, as in any institutional endeavor, they tie together inextricably. None is independent of the other. Whether acknowledged or not, each works in tandem with the others. They must be harnessed correctly and be suitable to each other. Such suitability implies that the triad components of science, organization, and engineering cannot be accidental handme-downs, and their relationship a chance one.

So, this trio of factors must consist of the proper science base, the proper organizational structure, and the proper instructional engineering. Together, the three constitute the triad model of education. The triad model of education relies upon a science whose subject matter is the analysis of behavioral contingencies-behaviorology. The educational organization in the triad model consists of a division of labor that is team-based and whose control and coordination operates through overlapping sets of cybernetically-linked systems of activities, and thus can be designated as 
collaborative. And the instructional technology of the triad model becomes an instructional engineering endeavor executed through contingency-based systems of instruction.

\section{Behaviorological Science}

Education consistently maintains its infatuation with tool technology. From Edison's long-ago cry that the movie projector will solve all of education's problems to the current hallelujahs over what the computer can accomplish, the latest delivery devices and computational gadgets are touted as the means to instructional salvation. The result: teachers stuck in the wasteland of deficient instructional tools. Any profound change in effective instruction will not be physically based, but behaviorally based. Instruction is the task of transforming repertoires. The tools and techniques provided by the physical sciences are ancillary to this task. Most of these tools, such as the internet, allow a larger number of students to be reached. But it is not the number of people who are reached that counts. What counts is the change in those who are reached. Change occurs through techniques that arrange contingencies that produce, modulate, and maintain actions. Those contingency-based techniques derive from a science that analyzes contingencies. (See Vargas, in press, for an overview.)

The science of contingency relations between actions and other events is behaviorology. The occurrence, intensity, and form of all actions depend on their contingent relation to other events, happening initially just after and then, just before those actions. Behaviorology is the analysis and synthesis of these contingency relations. Such analysis and synthesis covers all behavior, but behaviorology's underlying themas are few. A thema implicitly guides effort within a discipline. (For an analysis of the specific technical and philosophical meanings of "themas," see Holtan, 1973, and for their role in behaviorology, see Vargas, 1996.) Though all themas are equally important, three pertain particularly to contingency-based systems of instruction.

A first thema: The meaning of actions is in their relation to other events. The meaning of a physical event such as light or sound resides in physics until it is paired in a special way with activity. The light becomes a so-called "discriminative stimulus" when it evokes an action due to prior pairing with a "reinforcer." The meaning of biological events such as food or sex resides in biology until these are related in a special way with actions. Food becomes a "reinforcer" when it follows an action and increases the probability of actions within its class occurring in the future. The only evidence, of course, of such possible future occurrence is its manifestation in the past. Such a relational characteristic is one to be found in the older sciences. In physics, the meaning of a physical event is always in relation to other physical events. "Force" cannot be understood apart from "mass" and "acceleration," as the equation "Force equals mass times acceleration" ( F = MA) makes clear. These relations are embedded in the analysis of properties. Physical properties do not lead an ontological existence apart from the things in which they are discerned, but neither do they belong to those things. The speed of a car does not dwell in the car, nor, for that matter, in the road. It is a relation between the car and the road. Most individuals can understand the reasonableness of such an analysis. But it is still difficult for everyone, professional and lay person alike, to construe that a personality also does not dwell in a person. For some time a position advanced by behavioral scientists other than behaviorologists, though in their own fashion; William James (1882, p. 179) comments that “... a man has as many social selves as there are individuals who recognize him ...". Also difficult to accept is that the meaning of what a student says is not in the statement, but in the conditions under which the statement is made. With terms such as "cheating," everyone recognizes this distinction.

A second thema: Actions are contingent. "Contingent" carries two meanings. An event occurs only if another one does, and, its occurrence is only probable. The likelihood of lever-pressing in the future occurs only if food is provided to a hungry animal after pressing a lever in the past, but the future occurrence of lever-pressing is not inevitable. Other events may intrude. Whatever action comes about within a given set of circumstances is the vectored product of a number of forces that bear on it. The chanciness of predicted outcomes is especially acute in human affairs where cultural factors play a part. Technologies, especially those that are instructional, must give room to the nondeterministic contingent aspect to predicted outcomes. Not succeeding with a technique drawn from behaviorological science does not call for an immediate default to another science such as neurology. When a space-shot goes awry and blows up on the launching pad, the engineers do not discard their physics principles. They reexamine the conclusions they drew from them and the conditions under which those conclusions were applied. Behaviorological science is new, which is all the more reason to be sensitive to the chanciness of the effects produced with it especially in complex human situations such as the classroom. (This occurs even with so-called simpler species; for a number of interesting instances where actions well taught went astray, see Pryor, 1975.)

A third thema: Within the organism, no agency resides that causes its actions. Actions, as dependent variables, are due to the forces, specified as independent variables, that bear on them. (Even more exactly, it is behavioral properties descriptive of actions, such as rate, that result from the effect of a designated energy source, such as a schedule of reinforcement.) These forces may be inside or outside the body or in both places concurrently, and may be physical, biological, and behavioral. Physical forces may be as ubiquitous as the gravity that dictates the degree to which we move about on the surface of a sphere such as the earth 
or the moon. Biological forces may be as common as the actions of muscles, bathed in nutrients, that move us daily. Behavioral forces may be as widespread as the actions of others in text and speech that impel action and thought or stop it. These forces are not prescribed by an agency. The absence of agency has been well established in physical and biological analysis. No one now asserts that Zephyrus makes the west winds blow and Ceres the spring crops bloom. Common speech still concocts, however, an agency responsible for complex conduct, especially the conduct of humans, such as the agency of mind or self or even personality. But in the paired set of values of an independent variable to a dependent one as laid out in a graph, what room is there for an agency to act out? It is not a self that paces the actions of students through an instructional system, but arranged instructional contingencies.

\section{Collaborative Organization}

Commonly overlooked in the potential application of any instructional technology is how to organize to carry it out. Such organization is taken for granted. No one notices the tie-in between the current way of teaching and the current manner of organizing it. No one notices because the current structure of instructional organizations has been around so long that it seems right and natural. It seems right and natural that the teacher be someone who knows the subject matter. It seems right and natural that this person control the classroom situation by presenting material, by assigning tasks, and by motivating actions. It seems right and natural that the teacher meet with students at assigned times and places and that these students start and end at the same time with the same material and test at similar times. What seems right and natural both follows and undergirds the organizational model that prevails in education. A content expert presents the subject matter, usually by talking. A support staff supplies what is needed, from pencils and paper to computers and internet connections. A centralized administration issues school policies and procedures, and arranges for cohorts of students to pass through the various instructional levels at the proper times and places. This modal organizational scheme for instruction so conforms with every expectation and experience that it is not questioned.

The traditional education organization rests on a simple proposition: Information is prepared and transmitted, and then it is received and processed. As such, the traditional educational organization rests upon a transmitter (the teacher) who knows what to transmit and a set of receivers (the learners) who know how to process it. Though conventional educators and the lay public extol the format of the individual teacher in the classroom, anecdotes and statistics reveal the dismal reality of this type of organizational model. As Gould mentions,
My first teacher of paleontology ... lectured from notes on yellow foolscap that he must have assembled during his own days in graduate school. The words changed not at all from year to year, but the paper got older and older. I sat in the first row, bathed in yellow dust, as the paper cracked and crumbled every time he turned the page. (1976, p. 24).

Exceptions, of course, are given; persons such as Miss Mary Graves, B. F. Skinner's high school teacher to whom he dedicated his book on instruction. But the term "exceptions" is relevant. In every society, large numbers of students do not finish even their elementary school education, many who are capable do not get the opportunity to attend higher education, and, whatever the vagaries of grading, of those who do attend, only a small percent graduate with repertoires judged as excellent.

But if education is the shaping of repertoires, then a very different set of considerations ensues. The emphasis shifts to the intricate processes by which such shaping occurs. Organizationally acknowledging the complicated characteristics of teaching processes requires changing the division of labor necessary to carry them out. No one person can carry out all of these processes in a skilled and timely fashion. An alternative structure in the division of labor for teaching, and thus in its organization, reflects the complexity of instruction.

This alternative organizational structure takes into account the array of different processes involved in the teaching operation. These processes make up teaching; for teaching is more than assigning and presenting a subject matter. Teaching consists of arranging contingencies between repertoires and settings, and this arrangement occurs through a variety of complex operations. These operations consist of:

- the design of instruction

- the evaluation of instructional effect

- the presentation in various modes of a subject matter

- the logistics of repertoire and setting contacts at different times and places

- the in-depth exploration of the subject matter.

No one person has the skill and the time to know and to perform each of these operations in depth. Each operation requires its own expertise.

Different experts carry out these operations. There are experts in instructional design, evaluation, presentation, logistics, and content. Control and coordination of these differing special skills take place in instructional teams. These teams produce, present, manage, evaluate, and design their contingency-based instructional systems. The instructional team and the contingency-based instructional system interactively link in iterative reciprocity. Measured in explicit terms, outcomes guide the next system design. As repertoires of students are changed, these changes in turn alter the repertoires of instructional team members. The new actions of team members produce new instructional arrangements. This continuous reciprocal interaction drives innovation. 
Of course, there is more to an organizational structure than just instructional teams. These instructional teams cybernetically connect to other structural elements of the organization. The cybernetic arrangements make more sophisticated the reciprocal effects between teaching and administrative functions so that resource allocations tie to instructional accomplishment, not to number of students in a class. Innovative organizational setups become possible. For example, a more profound organizational layout than currently found in traditional educational organizations would be full time quality-control research centers. These centers would interact with the instructional teams. These research centers would obtain the latest information from the behavioral sciences that bear on making the instructional process more effective and share those data with the instructional teams. Currently, research findings about human behavior only dribble down to the classroom instructor. Typically such information drips haphazardly, with a workshop here, a circular there. In contrast, instructional system teams would integrate this information into their operations and share the results with the research centers. Together, Research Centers and Instructional Teams would work out the practical implications. It would be a reciprocally enhancing cooperative effort. Arranging the proper structure for an organization so desired is not a unique endeavor. A constant search goes on for the arrangements that produce optimal performance to achieve organizational goals. For example, an organizational ambition, especially in industry and commerce, is innovative action by employees. Instead of exhorting them "to think new" (as educational organizations exhort teachers "to teach better"), companies rearrange their structures to produce innovation in process and product. The rearrangements range from changing patterns of face-to-face contact to altering authority relations between reporting levels. To these new structural arrangements are attached new metrics in measuring productivity, as well as new types of rewards. The aim, of course, is not to make the mistake of thinking a creative innovator can be hired (as elusive as hiring a great teacher), but to set out the organizational contingencies by which innovative action is produced. In like manner, proper organizational contingencies yield effective teaching.

\section{Instructional Engineering}

Contingency-based systems go through an iterative process in which each team expert, in joint enterprise, contributes to the next phase of the system's design. Each phase provides an opportunity for incremental improvement in design and procedures. Procedures are checked against the science's principles. It is more than just a simple application of technology. Contingency-based instruction conforms to an engineering operation. But the traditional conventional perspective overlooks, or even denies, and certainly rejects, teaching as an engineering enterprise.
A survey was conducted by Latham (1999) in which he inquired of 80 randomly selected educators, engineers, lawyers, and physicians (20 each) how they solved problems "commonly experienced in their work" (p. 4). He specifically addressed the "basis for their solutions" and whether others in their professions would approach problems in the same manner. He found that the "most frequently given response by educators was, 'I just fly by the seat of my pants.'”(p. 5). The answers of physicians and lawyers and especially engineers refer to principles and laws when attempting to solve specific problems in their disciplines. The responses of engineers contrasted sharply with those of educators. The difference in problem-solving orientation between engineers and educators points to why results are so poor in all areas of education. Too many educators still consider instruction to be an art form. It is. But art, one's personal experience and style and skill, should be combined with science, the principles and laws that explain a realm of nature, including that realm known as "behavioral." Instruction should be that combination of art and science known as "engineering." Specifically, in education, it should be "instructional engineering."

The phrase instructional engineering denotes the explicit derivation of technical procedures from scientific principles. Liebman (2005, p. 296) describes the endeavor metaphorically but well. "... an engineer uses the fruits of science to feed the appetite of technology." It feeds this appetite in a different and more nutritious manner than connoted by "technology." Instructional engineering differs from instructional technologies that simply collect prior practices. These technologies are artisanal techniques discovered through trial and error. These practices tend to be successful only in a given setting or with a particular group - a repeated finding, by those such as the Gates Foundation who toss money and traditional solutions such as the small class or the charismatic principal at the "education problem." See for example, Greene and Symonds, 2006. With instructional engineering, however, a given technique finds its justification in a scientific principle and enhances its potency as it adapts to novel circumstances. The technique may not work well initially, but a scientific understanding facilitates finding out "why" and improving it. And if it works well, understanding of its principles expedites the next breakthrough. From aeronautical engineering to genetic engineering, engineering disciplines derive their systemic technologies from the frameworks of their parent physical and biological sciences. In education, the science of behaviorology provides the framework for contingency-based instructional systems.

Contingency-based instructional systems embody the specific forms of the engineering endeavors derived from behaviorology. They resemble each other only to the degree that they operate within the framework of the science and with the division of labor demanded by the instructional task. Otherwise they differ in the particulars shaped by specific circumstances. We can, however, provide a prototype 
of a contingency-based instructional system. The prototype gives an overview of the system's two fused components: "repertoire," and "setup." Each component consists of elements, such as "governance" in the repertoire component, and "objectives" in the setup component. At deeper detail, the attributes of the constituent elements characterize any contingency-based instructional system. A dynamic outcome ensues from the taxonomic scheme. The interaction of elements within and between the two sets of system components creates instructional consequences. As it is an open system sensitive to its consequences, the instructional system's contingent outcomes affect future features of the instructional environment. Note the significance of the phrase "instructional environment": It is not a person who teaches. It is an instructional environment that teaches. (See, for example, Hursh \& Tucci, 2005.)

\section{Instructional Setup Component}

The setup component of a contingency-based instructional system features five constituent elements: subject matter, objectives, quality control, presentation modes, and logistics. To some degree, these are found in most instructional arrangements. Even the crudest instructional arrangement (such as the lecture) contains most of these elements, though at a primitive level. The lecture "covers" a subject, the instructor tests for it, the presentation mode conveys the material through a talk, and the registrar arranges when and where the students assemble. In traditional instruction, these system elements are not well utilized. Few instructors use test results in a quality control fashion; for example, changing how they lecture based on what those results reveal. Some instructors deny that they have objectives, overlooking the ones implicit in what their tests cover. Most instructors do not schedule their students' instruction, but accept the registrar's arrangements of how and when groups of students encounter their subject matter. All instructors engage in a given presentation mode, typically the age-old one of talking in person. These system elements have been known for some time, and typically applied to groupbased instruction that batch-processes students based on the mythical average student. In contrast, contingency-based instruction deals quite explicitly with an instructional system's component elements of subject matter, objectives, quality control, presentation modes, and logistics, and addresses quite explicitly the central problem of mass education - the variability of student repertoires.

Subject-matter is disciplinary driven and ideologically driven. From anthropology and art to zither-making and zoology, it is obvious to acknowledge the effect of a discipline in a subject matter. Disciplinary information, the specifics of a branch of knowledge, presumably makes up a subject matter. Not so obvious is what is interpreted as the content of that discipline, and even more so, which aspects of that content should be taught to whom and at what grade level.
Independent of what is taught, there is the question of who is taught and how much. Many societies do not deem it proper to teach females literacy skills beyond a certain level of basic reading and writing, much less advanced mathematics and sciences. Western societies entertained this prejudice for many centuries. At best, females were said to be not capable of learning these subjects. At worse, it was believed they would be corrupted by them. For example, the American woman and author and early feminist, Mercy Otis Warren, was taught basic literary skills by her uncle but then, as Waters, the American historian, describes, she was

forced into ladylike needlework... All of this, she intensely resented and wrote that if females dealt with trifles and men with power, the 'deficiency lies not so much in [the] inferior contexture of female intellects as in the different education bestowed on the sexes.' (Morison, Waters, \& Flexner, 1975, p. 98).

More than one or two societies, or groups within them, still entertain these notions. Of course it is not only women who endure these inequities. For economic and other reasons, elites with power often ensure the subordination of a given class of people by restricting access to the basic asset for further capital-skill. Such effort need not be gross. Tax policies can price higher education beyond the reach of social classes of low income.

Another common aspect of a subject matter is how it is to be interpreted prior to its presentation. For example, it would seem that, as a well established science, the content of a biology course would be rather straightforward. But ferocious struggles are waged over the selection of biology topics, from those between scientists and creationists over intelligent design as an alternative to evolution, to those morally infused shouting matches between a number of indignant groups over the extent and degree of topics dealing with sexuality. And in teaching the politics of democratic societies, it is doubtful that any school at any level in any place in Florida teach the writings of Che Guevara as a guide to social planning while only a few miles south in Cuba, such writings would be a common part of the educational curriculum. What constitutes course content ensues from fierce battles at the local school board and in the highest offices of the bureau of education. In these matters, the teacher in the classroom has only a partial say, if that much.

It is doubtful that any instructional system or organizational arrangement would change the reality of such social infusion into the curriculum. But such reality underscores the fact that the teacher, the putative content expert, already shares authority with others over the subject presented in the classroom. Becoming part of a teaching team does not diminish whatever authority the content expert has over curricular matters. In fact, it enhances it. It underscores the fact that there is an expert in the subject matter. The rest of the instructional team contribute their 
special skills outside of the content area. (For further discussion on these matters, see Vargas, 2004).

Objectives address both the repertoires of individuals and the features of an instructional system. Each type of objective delineates the aims of an instructional system at different levels of analysis. For a class of individuals, behavioral objectives specify observable performances at a standard. For a long time, tests have played this role indirectly without specifying beforehand the performance desired. Even behavioral objectives can be too general when they deal with a cohort of students rather than the clearly defined repertoires of each student in a class. Behavioral objectives can distinguish individual students' repertoires, but that requires an instructional system both resource intensive and measurement savvy. (The measurement procedures of "Precision Teaching" address the activities of individual students. See, for example, Fabrizio \& Moors, 2003.) System objectives address the relation of instructional outcome to resources expended. Specifically, instructional outcome compares an aspect of performance over a time or fiscal denominator, or as combined. Currently, in traditional education, it is the rare instructor who specifies both system and behavioral objectives. These constitute, however, a necessary and integral part of a contingency-based instructional system.

Objectives change with iterations of the instructional system's operation. A brand new instructional system may start with a system objective of fifty percent of its students achieving within six months a high criterion level of mastery. On that system's second iteration, it may aim for a twenty percent improvement and state a goal of sixty percent achievement with the same requirements within the same time frame and with the same cost. With further iterations, cost and time factors become increasingly sophisticated. For example, the instructional team could take into account the amount of time a student takes to achieve a criterion level. All things considered, the less time demanded of the student to achieve mastery, the superior the instruction. Currently, too many instructors outsource the effort they should make in teaching by demanding greater efforts by students in homework. Homework effort is the student doing the teacher's job. In contingency-based instructional systems (C-bIS), increases in productivity come about through greater efficiency of operation. Iterations also change the quality and type of behavioral objectives. The same instructional system may start with its behavioral objectives at the knowledge level with all students achieving them within a fixed frame of time. Later, it alters behavioral objectives to fit flexible rates of achievement among the varying student repertoires. It brings in new objectives at the solving level, tailored to each student's interests. Eventually further individualization can occur and objectives at the creating level brought in. Both system and behavioral objectives continue to change as an instructional system evolves.
Quality Control, in some fashion, appears in every course, but typically in haphazardly poor form. A student studies an assignment at home, at the library, at the cafeteria, and no one observes what kind of contact that student made with the material. Traditional educational arrangements place students in a "teaching" situation (more accurately, in situations where they teach themselves), and later, frequently far later, tests those students. In the first week of school, students sit in a lecture room and listen, it is hoped, to what the instructor says, and eventually, those students take a test on some portion of what was said. The relation between instructional condition and performance effect is not observed, or if by chance observed, only observed in a nonsystematic fashion. What is necessary is to move away from so-called "testing." In "tests" no immediate point-topoint feedback exists between an instructional variable and a performance variable. Without this detailed feedback, evaluation of an instructional technology is at best crude and clumsy, at worst, misleading. And not only crude and clumsy and misleading; current grading arrangements compromise both instructor and student. Without directly measuring and observing the student's change in performance as it occurs, cheating proliferates. Not only cheating on the part of the students, cheating as well by teachers as when, driven by mandated standards, they are tempted to teach to the test. Furthermore, grading on comparisons between students - the norm ranking of what each student learned relative to another-perverts the instructor's accomplishment. In a class where material was poorly taught and poorly learned, fifty percent mastery on a student's part can receive an "A" grade, yet, because only a few "A's" are given, scholastic quality presumably has been maintained. And lastly, and as important, without exact knowledge of the relation between students' performances and instructional conditions, it is not possible over time for either an instructor's or an organization's performance to improve. Is there any university whose teaching practices and successes do not resemble those of the earliest universities of the fourteenth century?

In a contingency-based instructional system, quality control consists of three factors: standards, feedback, and evaluation. Standards must take into account future demands on student performances. Any later course that follows the current one will require entry repertoires that allow an instructional sequence to begin properly. A philosophy course requires complex reading and writing skills; a calculus course, mastery of algebra; lab and music courses, the deft handling of tools and instruments. Beyond that obvious requirement occurs a more subtle and profound effect: the relation between standards and repertoires. Standards in relation to entry repertoires bear upon an instructional system's design. For example: If standards are high and entry repertoires are weak, then the sequence of instructional units take longer to complete, passages between concepts become more detailed, and examples and illustrations increase in number. Similar 
considerations apply elsewhere such as with type of exit repertoire and social demands. Feedback is the specific pointto-point description of each student's repertoire as it contacts an instructional setting. Specific strengths and weaknesses of any instructional arrangement can then be specified not only in the usual manner of "errors," but also in such other properties as rate of positive change in the student's performance. In fact, the notion of "error" changes for it is as much a matter of "error" on the system's part as it is on the student's. Feedback becomes a hunt for reasons as to why a performance occurred as it did, and what aspect of the instructional setup was responsible. As specific descriptions of varying action properties are produced, the volume of data obtained becomes enormous both with respect to one student over time and many students concurrently and over time. Evaluation relates those data to objectives, standards, costs, and any other consideration deemed important by the system's designers. It may be worthwhile to reach a certain standard, but at what cost in time and money? These assessments involve policy considerations in the larger organizational context.

Presentation Modes are simply the means by which instruction is delivered. Everyone is familiar with machines in a variety of presentation modes: overhead, video, computer, and so on. Humans also are a presentation mode. They have two great advantages over machines. The first is interactivity, reacting to a characteristic of the student's performance and adjusting the next instructional feature to that characteristic. In this feature, the computer now comes close to matching the human skill. The second is emotional tone. Elements of sociability, warm regard, bonding, and other well known characteristics of human interaction enter into and are necessary in instructional settings. No machine can substitute for the specific emotional ties between humans. In other delivery conditions, a machine can do a better job than a human being. Machines present pictures and sounds in ways no human can match. Machines store data with a capacity and accuracy no human can approximate. Machines neutralize the negative aspects of certain sorts of social interactions. Machines display processes otherwise not possible or plausible to contact such as those that are too fast, too slow, or too dangerous. In such comparisons between machines and humans, it is not a question of the superiority of the one over the other. Human beings do not replace machines, and machines do not replace human beings. Each is useful in the instructional setting for which it is best suited. Neither teaches. The contingencies in the setting do, utilizing the presentation mode best suited for a particular lesson.

The latter point should be kept firmly in mind, for many are becoming enamored of so-called "E-learning," the use of the internet and other electronic means, to deliver information and thus, presumably, teach. People are charmed by the proliferation of computer stations, and rank as an upto-date teaching facility one with the greatest number of computers. A celebratory noise is made over how many students sit at each computer station. But books could just as easily be given to every student and the claim made that if students read the books, they are now taught. It cannot be overemphasized that a way of delivering instruction is not the same as instructing with what is being delivered.

Logistics orders the movement of students through the sequences and forms of instruction of an instructional system. For the classroom teacher in traditional instruction, logistics rarely presents itself as an issue. The registrar's office regulates when and where students encounter instructional arrangements. It designates the total frame of time of instruction (either the semester, the summer session, the four-week course, the twoday seminar, and so on), the partial length of time for instruction (an hour, more or less), and the specific hours and places of instruction (time of the day and site). The logistics arrangement reveals clearly that traditional education presumes a certain commonality among students. It adopts as an organizing principle the notion of an average student at a given level of knowledge and skill with the same capacity to learn within a given time frame. In traditional instruction, all students allowed entry into a calculus course are considered capable of understanding the material. If certain students do not do as well as others within the same time frame, then the finger of blame thumps those students. A variety of selfserving reasons are given-the students were not smart, not motivated, not attentive, and so on. Traditional education demonstrates the no-diversity principle of equivalent students through the factory-like batch processing of students. Students proceed in lock-step scheduling through the various stages of the instructional material. Little allowance is given for the diversity in student repertoires. The logistics arrangements of current education are built not only for the convenience of those running the educational organization, but also built on the assumption that students and student repertoires are more alike than different.

In contingency-based instructional systems, these logistics arrangements contrast considerably from those of traditional education. Since students differ in what they know, in how they know, and what they can do with what they know, the contingency-based pacing of students accommodates their extraordinary variety. Students start and end the lesson units of an instructional system at different times. They proceed through a sequence of material at different rates. They meet one-to-one or as a group with instructors at different dates and places. They encounter instructional arrangements in differing sequences. Depending on what the instructional designers think best, any given student may proceed through a sequence of instructional activities that differs from other students. To accommodate the complexity of these instructional arrangements, contingency-based instructional systems decentralize the logistics function and run the student through the teaching sites and time frames at the local level of an instructional system. Logistics requires its own expertise within the teaching team. 


\section{Instructional Repertoire Component}

Instruction, if successful, changes repertoires. It shapes them to given specifications. In whatever country, educational institutions prescribe a plethora of tests to certify that a particular repertoire is in place. Societies send students to schools so that students, whatever their behavior when they start, are to leave with behavior that is desired. To transform behavior from an entry to an exit repertoire characterizes the work of educational organizations. Specific technologies carry out this transformation effort. In any instructional setting, every instructional technology attempts its transformation effort in the three repertoire domains of governance, type, and variability.

Governance of Repertoire: Few people simply watch an action without providing a reason for it. Providing reasons, whether in the form of gossip or theory, is one of the most commonplace activities in which everyone engages. Neighborhood gossips speculate as to why a neighbor waters his lawn even on days it rained. Television talking heads pontificate as to why a particular politician voted as he did. Classroom teachers conjecture why students fail tests, and often say: "because they did not study enough." The general public celebrates the student who does well in a piano competition and the reason given is that she is "talented." Reasons are the causes offered as to why an action occurred as it did. A cause designates a relation between actions and the events that govern them. When events determine actions, they control them.

All actions reflect the control of properties of phenomena around us and within us. This control takes two forms: that from direct contact with those phenomena, and that from an encounter with the behavior of others who pass along the effects of their contacts. In the first case, that of no intervening factors, a direct encounter with events governs behavior. Actions are event-governed. The smell of coffee is unforgettable, and its scent first thing in the morning will have the early riser marching to the kitchen. In the second case, that of a mediated encounter, actions are governed by how other people's behavior reacted to those events, and from that reaction what they passed along lingually. Through the medium of language, cultural actions intervene between an event and its effect. Behavior is lingual-governed. Before the coffee is smelled, a speaker tells the reluctant riser "coffee is ready" and that statement results in the bed covers slung back. These two sources of governance dictate all activity. (For further discussion of the meaning and distinction between the two, see Vargas, 1988). In the design of an instructional system, both sorts of control are necessary and important.

Lingual-governed control turns out to be the larger portion of instruction. Most instructors simply tell someone how to do something, even in physical education. Telling "how" precedes the activity. "Hold the racquet this way." "Line your shoulders with your ears." "Place your thumb along the edge of your fingers." Much of what students learn of events about them and even events within them, they know from what others tell them. They are told of a place called "China." But how many of them have seen its monuments, smelled its pine trees, and heard the talk of its Beijing residents? They know because they believe what they have been told. They believe what family, friends, neighbors, priests, politicians, and, of course, teachers tell them. This is practical, for knowledge passed along allows efficiency. Guests could get quite hungry waiting for the host to figure out how the outdoor grill works. Someone just tells him and soon the hamburgers are done. What individuals know even of the intimate side of their own actions depends in large part on what others say to them. They understand the significance of their conduct only as that significance is pointed out to them through a long process of socialization. In socialization, other people's behavior mediates not only their contact with the world around them but also that world within. People observe in themselves what others teach them; "The Looking Glass Self," George Herbert Mead called it. An important part of formal education constructs the inner listener to the inner speaker, and how to share at least part of such speech with others. Students learn how to talk about what they observe in their inner world. A good portion of psychoanalysis-a type of one-to-one instruction-deals with such inner world observing and talking, for example, Theodor Reik's Listening With the Third Ear (1948), as well as does current behaviorological analysis, such as Skinner's Verbal Behavior (1957/2002), especially the chapters on self-editing. An empirical analysis of teaching such activity is Greer (2002), especially section II. Lingual-governed instruction readies and shapes actions in both the outer and inner worlds of individuals.

Event-governed control gives a direct understanding of the properties of events that are not, and often, cannot be obtained by what others say about them. Words are frequently too gross for the fine details and subtle shadings of events, or words are even not yet available for new events. (Poetry, of course, provides many examples: "Hope is the thing with feathers.") But words falter even in everyday matters. The difficulties of describing the taste of scotch are given by phrases such as "overtones of honey with a touch of heather and the aroma of sea spray especially in its long finish." And descriptions of wine run largely to analogy: "This foxy wine has bad legs." Many discoveries are preceded by far-fetched metaphors describing something newly encountered but with properties only dimly understood. In the beginnings of zoological description, new types of animals, fancied or real, were described with human attributes. ("... the sphinx which has brown hair and two mammae on the breast...". "[The hyena] imitates the human voice among the stalls of the shepherds; and while there, learns the name of some one of them and then calls him away and devours him.” pp. 50, 51, from Ley (1968) quoting 
Pliny the Elder's Historia naturalis). Words tell how other people behave towards events, but do not provide students with the behavior itself. Many skills are not doable until students contact the events about which they have been informed. They cannot know how to play the piano until they actually contact the keyboard. (Before that, they may know how to talk about how to play the piano.) A long history of pottery making informs the particular style of a culture's vases, but the pottery maker cannot produce a fine vase until he throws and spins the clay. That vase will then reflect not only that culture's history but the potter's. The history of every person is a singular one. Therefore any personal encounter with events produces, if only to the slightest degree, an outcome to an event that differs from what has been said about it. To enhance solving and creating behavior requires direct contact with a subject matter.

Both sorts of governance, event and lingual, play an important role in the effectiveness of our repertoires. Feynman (1985, p. 212) provides an example of how merely being governed by a text may not provide sufficient understanding of a topic.

But then I asked them how one could tell the absolute direction of polarization, from a single piece of polaroid.

They hadn't any idea.

I knew this took a certain amount of ingenuity, so I gave them a hint: "Look at the light reflected from the bay outside." Nobody said anything.

Then I said, "Have you ever heard of Brewster's Angle?"

"Yes, sir! Brewster's Angle is the angle at which light reflected from a medium with an index of refraction is completely polarized."

"And which way is the light polarized when it's reflected?"

"The light is polarized perpendicular to the plane of reflection, sir." Even now, I have to think about it; they knew it cold! They even knew the tangent of the angle equals the index!

I said, "Well?"

Still nothing. They had just told me that light reflected from a medium with an index, such as the bay outside, was polarized; they had even told me which way it was polarized.

I said, "Look at the bay outside, through the polaroid. Now turn the polaroid."

"Ooh, it's polarized!" they said.

After a lot of investigation, I finally figured out that the students had memorized everything, but they didn't know what anything meant.

In our terms: What students said was not under control of the contingencies relevant to their direct contact with the events of light polarization.

Of course, both kinds of control, event and lingual, pertain to any instructional setting. The proper kind of control from events usually starts with an instructional design that involves lingual directions. Feynman had to provide verbal clues to get the students' repertoires under control of the crucial physical phenomena. Simply bringing people into contact with events does not guarantee they will come under control of the critical properties of those events. A study attempted to teach college women to "self-discover" that still water in a bottle always remains horizontal. But simply putting them in a situation where they could observe the phenomena did not succeed in their achieving the correct conclusion. As the report stated in the abstract, "Among women college students who did not know that the surface of still water in a bottle is always horizontal, two types of specific task procedures designed to elicit self-discovery of the principle were ineffective." (Thomas, Jamison, \& Hummel, 1973, p. 173). Because events are present does not mean they will govern actions in a certain way, or even govern them at all. At least at first, some degree of lingual governance may be and often is necessary. The important conclusion cannot be emphasized enough: Neither type of control is superior to the other, and the ratio of the kind of controls necessary will vary for the instructional case at issue. Directly contacting events facilitates a unique approach to those events and facilitates understanding of how they work independently of how they are said to work. Mediately contacting events facilitates efficiency in how to behave effectively and facilitates moving quickly to the next phase of an appropriate action or to the solution of a problem. Instructional excellence requires both types of governance for knowing a subject, for solving problems with it, and for creating new renditions of that subject matter.

Type of Repertoire: A day rarely passes in which awareness of something new does not occur. Schooling accelerates knowing new things. But in everyday life, becoming knowledgeable occurs so automatically it is hardly noticed. Such new knowing varies from the prosaic, almost beneath notice, to the profound, a just learned significance that may change one's life and that of others. Often, what was just learned implies action for the immediate present or the far future; actions that may consist of solving a problem for an effective personal and social outcome. The radio tells of a traffic jam on the route to our job, and we worry about getting to work on time. The newspaper reports on a lowering of interest rates, and we wonder whether we can lower our home mortgage. We do more, however, than find out what is going on and simply react to its effects. We solve problems with what we now know. We solve the problem of getting to work on time by taking an alternative route that avoids a traffic hold-up. We solve the problem of getting the lowest mortgage rate by calling several banks and comparing their rates, loan years, and loan points. Sometimes the problem we solve leads to an unusual solution uniquely influenced by our background. A unique solution not explicitly anticipated but useful, if for no other reason than it pleases, is said to be creative.

All instruction deals with three universal types of repertoires: knowing, solving, and creating. In knowing, the objective is to ensure that the belief systems of a culture are well transferred, often even well indoctrinated. Whether 
it is knowing the times table or the metric system, a pledge of allegiance or a pledge of abstinence, a theory of evolution or a theory of creation, pertinent social groups demand that repertoires repeat this material to exact specifications. Most of education consists of passing along what powerful groups within a society consider important for students to know. In solving, such knowing is taken for granted. What is required is a repertoire that is effective with known material when encountering unanticipated circumstances. Frequently those issues called "ethical" pose problems because considerations are vague and consequences uncertain. Can the concept of a person be applied to a set of cells? No simple "yes" or "no" suffices. In science, such solving behavior is highly prized, for the nature of scientific work is to start from what is known in order to explore what is not. Solving behavior starts within current boundaries of what is known. Creating takes solving behavior a step further. Creating behavior applies solving-skills to produce questions not previously considered. Alternative solutions are offered within a different framework of analysis. Darwin's theory of natural selection offered a different solution to prior answers as to why forms and functions of plants and animals changed over time. Darwin did not raise the usual question of how a supernatural creator creates new species. (There was already the available answer, "it just does.") Darwin raised the question of how new species arise within the framework of the world we observe about us. Einstein's theory of relativity-actually one of invariance of observations within different frames of reference-posed classical physics problems within new definitions of space and time. As the examples illustrate, the repertoire domains of knowing, solving, and creating blend together. Each domain, however, builds upon the other.

Differing repertoire types call for differing instructional technologies. But since these three types of repertoires have not been clearly discriminated, technologies pertinent to one type of repertoire, say "knowing," are condemned as faulty in themselves when the fault follows from inappropriate use for another type of repertoire, say "solving." A technique meant to ensure that someone can repeat the times table in the future is not appropriate for teaching how to solve a multiplication word problem. Criticism is misplaced when technical and instructional context is ignored. Proper teaching must focus on the properties of the technologies needed for the differing attributes of repertoires. Criticism is inappropriate when it states, for example, that a particular technology is good only for "rote memory" when that is exactly what should be taught in the most effective way. Who argues against "understanding" when students do have the skills to construct their own solutions? But trying to teach "understanding" without underlying skills leaves students befuddled, confused, and frustrated. Such criticisms, as well, do not take into account the relation between objectives and technologies. Objectives differ within each domain type of repertoire. For example, becoming skilled in how to solve a problem denotes a different set of behavioral capabilities than remembering at a later date the algorithms for already solved problems. To teach specific skills within these different behavioral domains requires different techniques, perhaps multiple exemplars in one case and fluency in the other. Another example: Much of solving and creating behavior involve superordinate actions that change the relation of one's own prior actions to other actions and events. Many, or most of these, are covert. Therefore, the implicated instructional technologies must deal with properties of actions that cannot be observed directly but only inferred. Each type of repertoire-knowing, solving, and creating-calls for its own appropriately designed technology.

Variability: The critical and vital characteristic of classes of actions is variability. Any set of students will reveal an extraordinary range of actions. The closer we inspect two instances of an action, the more likely a difference will be found. Regardless of the kind of action designated, it never is exactly the same from time to time, from situation to situation, from person to person. Prior to or even after instruction in a given subject matter, no two students know exactly the same "amount," as designated by some standard. And with respect to the amount they know, what is known in that amount is never identical; certainly if the amount tested is large. In a history course, one student may know a date; another, a name, yet score the same in "tests." Furthermore, even when what is known is roughly the same, repertoires differ with respect to what can be solved with what is known. Two students may know the Pythagorean Theorem, and only one applies it successfully to a given problem. And of course, by definition, every repertoire differs with respect to its creative expression. Asked to write a sonnet in the Italian mode, when writing independently, no two students will provide an identical sonnet. Whether considering the behavior of only one student or of a set of students, such behavior always displays diversity.

The diversity of repertoires results in two instructional operations that occur in every classroom. Instructors attempt to have all students behave the same and to have all students behave differently. Overlooking the necessity of the two apparently contradictory efforts produces a lot of needless argument. Though not acknowledged, instruction always endeavors to produce both convergence and divergence. In convergence, instruction narrows the diversity of a given class of repertoires until all repertoires are standardized with respect to a criterion. Everyone must give the same answer as to what is up or down, right or left, two plus two, one minus one, a fugue or a sonata, a rondo or a scherzo, a planet or a star, the capital of Spain or of France, and on. All societies, all schools, all educators engage in this sort of instruction. They want students to know the prior activities effective for that culture and to know the belief systems deemed important by the elites of that culture. Concurrently, in divergence, the range of repertoires is expanded until 
repertoires differ as much as possible. Educators promote this effect with many clichés and phrases; for example, it is said to be of great import to think "outside of the box." A problem in mathematics may be given in which the aim is not to provide a solution, but to provide a procedure that differs from the usual one of obtaining a solution. Efforts to teach so-called "self-expression" and "self-fulfillment," through activities such as the writing of haiku, make explicit the divergence aim.

But a gap exists between the reality and the rhetoric. Michelle Feynman (2005, p. xx) mentions this gap in an incident with her father, Richard P. Feynman, the Nobel physicist, "When I was in high school, he started showing me shortcuts in my math homework that diverged from the teacher's methods. I was subsequently scolded by my Algebra II teacher for not solving the problem in the right way." Divergence has a great press, but apparently few takers. How many of these incidents occur in subtle and constant ways in classrooms, and other social settings, is hard to say.

The ratio of convergence and divergence effort in the classroom is as much a political matter as it is a technical one. Societies differ considerably on the degree of variability they will tolerate and teach. They may "drift" into allowing only a narrow range of actions and beliefs. The Ming Dynasty ushered in a period of extreme conservatism. Among many examples, Kennedy (1987, p. 8) points out that "Printing was restricted to scholarly works and not employed for the widespread dissemination of practical knowledge, much less for social criticism." Many of the gains of China's past were allowed to erode. Kennedy also notes that over time, the Ottoman Empire grew more conservative and restrictive. "[It] increasingly suffered from some of the defects of being ... severely orthodox in its attitude toward initiative, dissent ... [T] he bureaucracy hardened, preferring conservatism to change, and stifling innovation" (p. 12). Such aims are reflected in school curricula. Regardless, however, of the attempt to have one overarching religious or political (or both in sync) belief system, most societies, as their technologies and economies become more complex, begin to demand a wider range of skills and a deeper level of specialization. (An elite, however, can become sufficiently comfortable with its life style, or religious ideology, that no further progress in productivity seems necessary. Instead, specialization increases in entertainment and art forms, including the art form of "living well" or "living properly.")

In education, these skill and specialization demands first manifest themselves at the organizational level in the design of convergent and divergent requirements in the curriculum. Student repertoires, brought together in the "basics," then are shifted into different disciplinary "concentrations." From school boards to faculty committees, educators spend a great deal of time on these "innovations." Often, the concern is that there is not sufficient "divergence"; that students are not sufficiently acquainted with the two cultures of the sciences and the humanities. Even more, critics contend that within each of the "cultures," there is too much specialization. Instead of the usual two-dimensional array of courses, physics, chemistry, biology, and so forth, each with its usual "string of pearls" topics separate from those of other courses, Holtan (2005, pp. 201-208) argues for a "mosaic" of topics, each interrelated with those of other courses. These efforts are not trivial. But they should not be confused with the engineering technology of instruction. Though their claimants often assert them as improvements in instruction, these changes are not innovations in instructional process.

At the instructional level, each instructional setting attempts both convergence and divergence. Students must learn terms and forms of Spanish understood by Spanish speakers before they can write an essay in Spanish. The equations of algebra and calculus are the same world wide and these must be learned before a complex problem in intercepting a comet or achieving a Mars landing can be solved. To be creative one must know something with which to be creative. One cannot compose music without knowing its sounds. (Beethoven's deafness happened after such knowledge.) No one can write a poem without knowing a language, and more than that, without knowing its rhythms and terms. These are established educational clichés for establishing conformity and then teaching diversity. It is the nonestablished ones, as in the Michelle Feynman example, that educators find hard to understand and tolerate. Convergent and divergent operations are always in uneasy tension. To gain the benefits of both requires accepting their dual presence.

Not making the distinction between convergence objectives and divergence objectives and not accepting the necessity of both has led, and continues to lead, to futile and emotional arguments. These spill over into the prior considerations of proper instructional technology. As pointed out, the disagreements over so-called "memorization" and so-called "understanding" miss the point. These disagreements exalt only one type of repertoire, as if the other were not equally important. The general issue is how, within the same instructional setting, repertoires are converged with respect to what must be known and diverged with how the knower treats what has been learned.

\section{Final Remarks}

Engineering from behaviorological science produces contingency-based instructional systems. The two components of all contingency-based instructional systems are the student repertoire and the instructional setup. The repertoire and setup components include all possible elements of an instructional system. Take one feature, that of governance: All instruction arranges for students to encounter the world directly as well as through what others say about it. Or take another feature, variability: All instruction teaches 
students to become more alike and more different in what they say or do. And so on. The repertoire component includes all possible permutations of the elements relevant in transforming student actions. The setup component covers all possible instructional circumstances that students may encounter.

Note that elements within the Triad Model's instructional system's components of "repertoire" and "setup" are category names for classes of variables, not the variables themselves. Within each category, the actual events and their properties, when observed, handled, and controlled, are then designated as variables. For example, within the repertoire component, the category of "governance." It is further classified into event-governed and lingual-governed. Lingual-governed consists of lingual units and their functional relations to the events responsible for them. When functional relations are designated for specific lingual units, this appoints those relations with independent and dependent variables with ascribed values. Following Skinner's analysis (in Verbal Behavior, 1957/2002) of lingual units, a given functional relation can be described by the independent variables at issue; whether, for example, a verbal relation is of the sort called a "tact." The properties of these relations are thus available for investigating their validity or engineering them instructionally. (Greer, his colleagues, and his students such as Greer \& Keohane, 2005, provide a good example of this effort. It is more than a good example, however, as it exemplifies "development" within the behaviorological domain. Their systematic and empirical effort reveals cultural evolution at work; how complex behavioral and lingual forms develop through the successive shaping of contingency-driven action forms at the individual level.)

The setup and repertoire components described can be found in any instructional setting, if only in incipient form. Unfortunately, in various degrees, instructors neglect them. Most are overlooked. Their properties are not well delineated. Technologies inappropriately address them. Their complexity is barely appreciated. Their difficulties treated in inappropriate and superficial manner. From the start of formalized instruction, solutions to the problem of effective instructing and learning have been along the lines of a better chalkboard, stronger family values, and a rigorous application of the paddle. But overlooking the separate and subtle elements of setup and repertoire components presents only a first difficulty as to why instructional engineering proceeds so slowly. Perhaps a greater difficulty in the design, execution, and assessment of instructional systems are the interactions of setup and repertoire components. This latter consideration will be taken up in a later article.

\section{Conclusion}

Currently, few teach by systematically manipulating the values of the variables of the repertoire or the setup component while holding constant other variables of these components. Much of this oversight has to do with attempts to seek an explanation for instructional effects in a dimension of inner being that is either neurological or psychological. By depending on these neurological and psychological realms and by basing instructional technologies on the attributes postulated by those realms, educators overlook the complexity of the behavioral dimension. They abandon the potential feast of behaviorological science for the few crumbs they can gather from other disciplines.

With behaviorological science, instructors can engineer the interaction of repertoire and setup components. Such designed interaction and its outcomes continually create new instructional techniques based on instructional contingencies derived from the parent science. A number of these have already appeared and they continually emerge. No particular technique defines contingency-based instruction. Contingency-based systems of instruction go beyond any given specific technique such as programmed instruction or precision teaching. But to note the circumscribed nature of these techniques does not imply abandoning them. These good techniques belong to the set of technologies that ensue from a contingency analysis of the instructional setting. Other techniques will by and by arise as the analysis rightfully inheres to the intersect of contingency and action. Such an analysis forces an appreciation of the complexity of the instructional task and of the resources necessary to carry it out. It is a task that must take into account not only the classes of actions of one individual, but of many.

The industrial revolution made mass education imperative. A society based on machinery instead of muscle required workers with sufficiently good repertoires to follow complex directions and read simple instructions. The service economy and the participatory polity now makes the demand for literacy greater. But one problem has always bedeviled mass education - the problem of variability. Not the problem of variety in body; that is easily handled. No. The critical problem in educating large numbers of people has always been and always will be the diversity in the range and depth of repertoires. It is a problem made especially acute by trying to reach a common standard while concurrently attempting to achieve the excellence of which each individual is capable. It is not solved by slogans such as "Leave No Child Behind." Nor is the problem solved by electronically expediting what is done badly. Educators can solve the problem, but not by placing a computer and a video in every classroom. Computers and communication media provide the roadbed to transport instruction. But tailoring that instruction to the individual repertoire requires other means, behavioral means. Such customized instruction travels only by means of contingency-based instructional systems operating within reorganized educational institutions. 


\section{References}

Fabrizio, M.A., \& Moors, A.L. (2003). Evaluating mastery: Measuring instructional outcomes for children with autism. European Journal of Behavior Analysis, 4, 23-36.

Feynman, R. P. (1985). Surely you're joking, Mr. Feynman! New York: Norton.

Feynman, M. (Ed.). (2005). Perfectly reasonable deviations: The letters of Richard P. Feynman. New York: Basic Books.

Gould, S.J. (1976). This view of life: Ladders, bushes, and human evolution. Natural History, 85, 24-31.

Greene, J., \& Symonds, W.C. (2006). Bill Gates gets schooled. Business Week, 65-70.

Greer, R.D. (2002). Designing teaching strategies. London: Academic Press.

Greer, R.D., \& Keohane, D. (2005). The evolution of verbal behavior in children. Behavior Development Bulletin, 1, 3147.

Holtan, G. (1973). Thematic origins of scientific thought: Kepler to Einstein. Cambridge, MA: Harvard University Press.

Holtan, G. (2005). Victory and vexation in science. Cambridge, MA: Harvard University Press.

Hursh, D.E., \& Tucci, V. (2005). Effective learning environments. In G. Sugai \& R. Horner (Eds.), Encyclopedia of Behavior Modification and Therapy: Vol. III, Educational Applications (pp. 1286-1290). Thousand Oaks, CA: Sage.

James, W. (1882) Psychology. Briefer course. New York: Holt.

Kennedy, P. (1987). The rise and fall of the great powers. New York: Random House.
Latham, G.I. (1999). Management, not “discipline.” Logan, UT: Mountain Plains Regional Resource Center, Utah State University. Ley, W. (1968). Dawn of zoology. Englewood Cliffs, NJ: Prentice-Hall. Liebman, M.N. (2005). An engineering approach to translational medicine. American Scientist, 93, 296-298.

Morison, S.E., Waters, J.J., \& Flexner, J.T. (1976). Three great ladies helped create the United States. Smithsonian, 6, 96-100.

Pryor, K. (1975). Lads before the wind. New York: Harper \& Row.

Reik, T. (1948). Listening with the third ear. New York: Farrar, Strauss, \& Co.

Skinner, B.F. (1957/2002). Verbal behavior. Cambridge, MA.: B. F. Skinner Foundation.

Skinner, B. F. (1968). The technology of teaching. New York: Appleton-Century-Crofts.

Thomas, H., Jamison, W., \& Hummel, D. D. (1973). Observation is insufficient for discovering that the surface of still water is invariantly horizontal. Science, 181, 173-174.

Vargas, E.A. (1988). Verbally-governed and event-governed behavior. The Analysis of Verbal Behavior, 6, 11-22.

Vargas, E. (1996). Explanatory frameworks and the thema of agency. Behaviorology, 4, 30-42.

Vargas, E.A. (November, 2004). The triad of science foundations, instructional technology, and organizational structure. The Spanish Journal of Psychology, 7, 141-152.

Vargas, J.S. (in press). Applied behavior analysis for educators. New York: Erlbaum.

Received October, 21, 2006 Accepted May, 23, 2007 